\title{
SIMULATING THE SPREAD OF COVID-19: A CASE STUDY ON WUHAN
}

\author{
Md Zamanur Rahman \\ w1757464@my.westminster.ac.uk \\ Kathryn Liddle \\ w1712301@my.westminster.ac.uk \\ Olawale Betiku \\ w1623075@my.westminster.ac.uk
}

\author{
Christopher Hitchin \\ w1706795@my.westminster.ac.uk \\ Sifi Bahuleyan \\ w1746454@my.westminster.ac.uk \\ Thierry Chaussalet \\ chausst@westminster.ac.uk
}

School of Computer Science and Engineering
University of Westminster
115 New Cavendish St, London, W1W 6UW

\begin{abstract}
We have a long history of pandemics. But the severity and fatality of COVID-19 concern the entire world and attracted the R\&D, media, and billions of people worldwide. Under this purview, the study aims to simulate the peculiar spread of the COVID-19 virus, which allows us to see the impact on Wuhan's deaths and recoveries. The study considered the basic 'SIR' model using five scenarios: with 'all measures, social distancing, isolation, isolation and social distancing, and no measures' situations to understand the pattern of the spread of COVID-19. It found a significant impact on these different interventions. The death rate is seen as the highest with no support scenario and has reached the lowest with the isolation and social distancing scenario. Moreover, it also showed that any action taken significantly affects the number of people infected, the number of recoveries, and the number of deaths.
\end{abstract}

Keywords: Simulation modelling, SIR, COVID-19, Social Distancing, Isolation

\section{BACKGROUND}

On 31 December 2019, a cluster of pneumonia cases of unknown aetiology was reported in Wuhan, Hubei Province, China. On 9 January 2020, the China CDC (Centre for Disease Control and Prevention) reported a novel coronavirus as the causative agent of this outbreak, coronavirus disease 2019 (COVID19), and 44 cases were reported to WHO by the national authority of China (ECDC, 2020). Later, it was spread to different territories of Wuhan, including Hubei as well as Thailand, Korea, and Japan, as reported by the WHO in its first situation report. After that, WHO updated Clinical Management Guidance for COVID-19, released their preparedness and responses when spread globally in their 52nd situation report. WHO declared a global health emergency on March 12 (WHO, 2020). It has now spread to 187 countries and over 3.84 million people with a fatality volume of over 0.269 million (Johns Hopkins CSSE, 2020). The severity and fatality of concern expressed by the R \& D of the whole world have attracted a great deal of media attention, with billions of people going into lockdown across the globe (Buchholz, 2020)

\section{LITERATURE REVIEW}

We have a long history of pandemics, however we did not know when the pandemic would occur or how severe it would be. It could cause an outbreak resulting in millions of fatalities. Under the circumstances of the absence of reliable Covid-19 pandemic exposure systems, computer models have become important information tools for all concerns. They can help provide global insight into the outbreak's behaviour and spread of infectious diseases in a given population, with varied geographic and demographic features. There are different studies on epidemiological modelling approaches. Here is a summary of the literature review to find the proper approaches and parameters. 
The study of mathematical models for the spread of infectious diseases is an important issue in epidemiology. Given the real world, a theoretical model of the spread of infectious diseases is proposed (Zhong et al, 2009; Lynch, 2020). The classic SIR model (Susceptible-Infectious-Recovered) is based on ordinary differential equations developed by Kermack and McKendrick in 1927. It was successful in predicting the behaviour of some epidemics (Hethcote, 2000). Another study (Daley, 2008) found that the spread of infectious diseases crucially depends on the pattern of contacts between individuals, whereas Stehlé et al (2011) found some limitations regarding person-to-person contacts, which is also found in Chen et al (2020). Another study (Vynnycky and White, 2010) found some critical features like basic and net reproduction numbers and the herd immunity threshold of infections, and the reasons for epidemics. The study by Cecconi and Barazzetti (2020) found that work, social relations, and leisure have an impact on the spread. They also found social distancing to slow down the rapid spread of COVID -19 in Italy.

Mac Hyman of Tulane University categorically mentioned in his Mathematical Modelling of COVID-19 the relation and importance of the number of tests with the spread of this pandemic (Mac Hyman, 2020).

A System Dynamics (SD) approach can help us understand the rapid spread of an infectious disease such as COVID-19 and generate scenarios to test the effect of different control measures (Bordehore et al., 2020). However, within a given population, diseases can spread at different rates over time due to the natural random nature of contact between individuals in the population. But here, SD has the limitations of no variation in output with a fixed rate of contact (Forrester, 1961). Subsequently, the simulations are repeated with different input parameters by applying a Monte Carlo simulation with no variation (Stan, 1987).

On the other hand, Khalil et al (2012) found that the variables used for using Agent Based Models $(\mathrm{ABM})$ are social agent attributes, distribution of population, and patterns of agent interactions whereas Hack (2019) found that human mobility is a key element in studying the large-scale spatial transmission of infectious diseases and improving epidemic control. In the case of super-spreading MERS-CoV, simulations of the epidemic show proportionality to the super-spreading effect (Hossain et al, 2017). The rapid growth in computer power has enabled ABM to consist of autonomous "agents" that interact with each other and have varying characteristics (Lynch, 2020). There are situations for which ABM can offer distinct advantages to conventional simulation approaches (Macal and North, 2006). It is demonstrated that the dynamic spatial interactions within the population lead to high numbers of exposed individuals (Perez and Dragicevic, 2009) whereas Chen et al (2020) mentioned that simulation can be used to predict the spread of the disease.

\section{PROJECT GOAL AND SYSTEM DESCRIPTION}

The primary purpose of this project is to simulate the strange territory spread of the COVID-19 virus, deaths, and recoveries. This will allow us to see the potential impact of Wuhan and understand how control measures affect the virus' spread.

\subsection{Flow Diagram}

The classic SIR model (Hethcote, 2000) assumes that individuals transfer between categories with a certain probability where $\beta$ is controlling how much the disease can be transmitted through exposure, determined by the chance of contact and probability of disease transmission $\gamma=$ how much the disease can be recovered in a specific period. Our proposed model is an extension of the classic SIR model Our population is divided into six categories: Susceptible, Infected, Isolated, Not Isolated, Recovered, and Death (Figure 1) where each was changing over time with a given probability to make the model more realistic. 


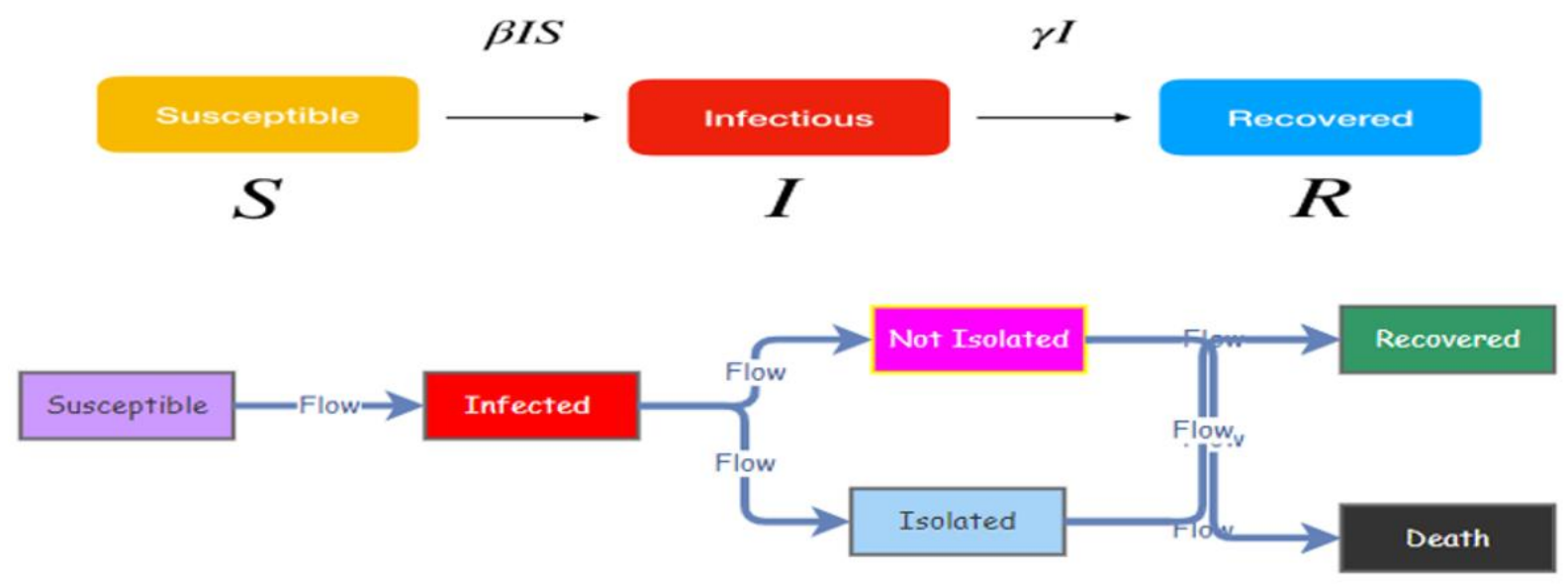

Figure 1 Classic SIR and Proposed SINIRD Model Flow Diagram

\subsection{Assumptions}

- The population is closed in that no additions are made to the susceptible population as births and immigration are ignored. The only way an individual leaves the susceptible group is by becoming infected.

- Once someone enters the recovery population, immunity is assumed so they cannot re-enter the susceptible population.

\subsection{Key Variables}

Since the model is based on the SIR model, the parameters are also based on three phases. The parameters are self-explained in the diagram. In the first phase, the parameter is with the parameter susceptible, which is the assumed population of Hubei. In the next phase, we included the infected stages are split down into three stages where a healthy person is infected, without and with symptoms for keeping them in Isolation. Recovery and Death are the 3rd phases for both isolated and not isolated states. There are 17 variables among which is Healthy, Infected, Isolated, Not Isolated, Recovered and Dead are the 6 states of the population: Social Distancing, Transmission rate, Vaccine, Total Ill, \% Isolation, Incubation, Recovery Rate, Illness Duration (for recovery), Illness Duration for (for dead) Hospital Beds, Death Rate are the 11 key agents. There is a specific formula behind the variables. Despite being suggested by a literature review (Mac Hyman, 2020) that the number of the test has a strong relationship with the spread of COVID-19 but due to lack of data, these parameters are not considered due to some data constraints.

\subsection{Various Types of Simulation in Epidemiological Modelling}

In a search to understand the behaviour of infectious diseases spread model and predict the pattern of diseases through a population, several attempts were initiated.

The earliest accounts were carried out in 1927 by Kermack and McKendrick (Hethcote, 2000). Following the SIR model, other physicians tried SEIR (Susceptible-Exposed-Infectious-Recovered) and ISEIR (Immunized-Susceptible-Exposed-Infectious-Recovered) models (Hethcote, 2000). However, mathematical models did not consider factors such as variable population structure and dynamics of daily individual interactions, which drove more realistic modelling results (Bonabeau, 2002). To overcome these limitations, ABM come up with extra leverage tracking the effect of social interactions on individual entities.

Several studies found the advantages of using ABM, which consists of a population of agents, an environment, and a set of rules managing agents' behaviour (Perez and Dragicevic, 2009). Each agent has two components: a state and a step function. The agent state describes every agent's attribute values in the current state. The step function creates a new state (usually stochastically) representing the agent attributes at the next step. The great benefit of agent-based models is that these models allow epidemiological researchers to do a preliminary "what-if" analysis to assess systems' behaviour under 
various conditions and evaluate. This is an alternative control strategy to adopt to fight epidemics (Perez and Dragicevic, 2009).

ABM also helps answer the issue of validation (Oberkampf and Trucano, 2002). Unlike System Dynamics (SD), which uses a top-down approach to model the system in ABM simulations, the system is "brought about" by carrying out lower level interactions between the agents. For this reason, ABM is beginning to be used in a range of fields, including biological simulations and social sciences, representing people as interacting agents in environments. ABM simulations can produce different output results for each run based on knowledge of the local interactions of the underlying agents and without making any changes to the input parameters. A study by Ahmed et al (2013) shows the influence and effect of variation within these two distinct simulation paradigms and shows that the ABM simulation of the epidemiological SIR model is more effective at capturing the natural variation within SIR compared to an equivalent model using SD with Monte-Carlo simulation.

\section{KEY DATA}

The 2019 Coronavirus (COVID-19) has turned into a global pandemic with unprecedented challenges for the worldwide community. Understanding the state of the disease and planning for future trajectories relies heavily on data on spread and mortality. But the unfortunate thing is the official data coming from various countries are highly unreliable (Stevens, 2020; Ghaffarzadegan and Rahmandad, 2020).

\subsection{Data Source}

The primary data source used was the number of cases, recoveries, and deaths published daily by the World Health Organisation and Johns Hopkins University and broken down by country and state (CSSEGIS and Data, 2020). Our study focused on Wuhan, where the outbreak started. As of 30 March, $10.4 \%$ of cases were in China, and $83.2 \%$ of these were in Hubei. Other information, such as the incubation period, hospital beds, and when lockdown began, were also used to inform parameter values (ECDC, 2020; CSSEGIS and Data, 2020; Wu Pei Lin and Lin, 2020, Reuters, 2020). We model the outbreak in Wuhan with individual reaction and governmental action (holiday extension, city lockdown, hospitalisation, and quarantine) based on some parameters of the 1918 influenza pandemic in London, United Kingdom (Lin et al., 2020).

\subsection{List of major assumptions}

- All humans are susceptible to 7.8 billion (as of February 2020) (Chamie, 2020).

- No one is immune to the disease as it is a zoonotic virus (it originates from another, yet unknown, animal).

- Those who recover are immune to the disease (at least if there is an outbreak). Seasonal human coronavirus produces immunity to these viruses which last longer than that of seasonal influenza but assume it is not permanent (Bai, 2020)

\subsection{Fitted Distribution and p-value}

As we know, an ABM is a computer programme that implements a Complex Adaptive System (CAS) by simulating its behaviour. The CAS describes the probability distribution of outcomes for each vector of inputs $\mathrm{x}$ and equation parameters $\mathrm{p}$, and the $\mathrm{ABM}$ simulates the probability distribution (Blume, 2015). In our model, \% of case change has exponential Distribution, whereas the death rate has got the beta distribution.

\section{PROPOSED MODEL}

The proposed ABM model involves 6 population states and 11 agents' rules which govern the behaviour of the agents (see Figure 2). Agents represent the human population, in which each agent is involved in a sequence of daily basis activities according to the agent's social environment. 


\subsection{Correct usages of model}

$\mathrm{ABM}$ is widely used in population health, especially with modelling the spread of infectious disease. A bottom-up approach helps us in providing global insight into the spread of contagious disease outbreaks' behaviour in a given population and transmission dynamics irrespective of geographic, demographic features, and social structure (Perez and Dragicevic, 2009).

\subsection{Limitations}

- There is a chance of fake news and unreliable data we use - much of this has been circulated on social media (Purohit, 2020; Ghaffarzadegan and Rahmandad, 2020).

- There is also a proportion of unreported cases as people may not feel the worst symptoms (Neergaard, 2020).

- Unable to validate or compare the results with ABM using insight maker.

- Frequent changes in data are unstable due to the condition of the agent's behaviour and time series

- The data is inaccurate; people might not declare their symptoms to avoid being isolated, quarantined, or hospitalised.

- ABMs can be more challenging to analyse, understand, and communicate than traditional analytical/ mathematical models (Wainwright and Mulligan, 2013).

- Unable to consider the social activity level, daily movement, spatial location, infection time, social type, and agent social networks (Khalil et al, 2012).

\subsection{Model Layout}

As mentioned earlier in the flow diagram, our model contains six states an agent can be: susceptible, infected, not isolated, isolated, dead, and recovered. Specific parameters affect the probabilities of agents moving between states. The parameters were changed to investigate how they impacted the spread of COVID-19, deaths, and recoveries. Figure 2 shows a conceptual ABM model diagram of the interactions of the different variables and parameters considered.

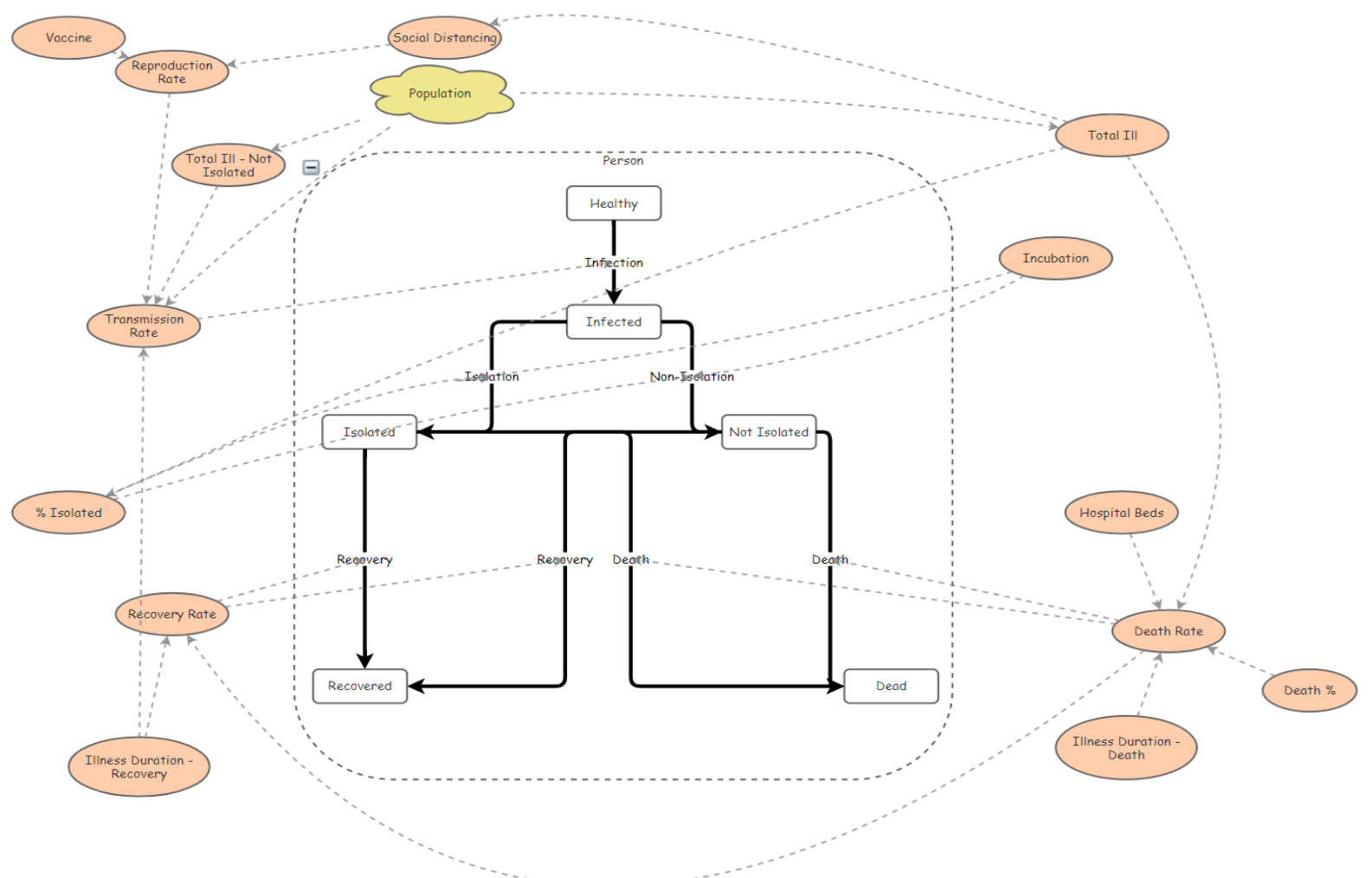

Figure 2 Conceptual Model Diagram

(Available at https://insightmaker.com/insight/211859/DZR-Model) 


\subsection{Scenarios considered}

In the study, five scenarios were considered where the control measures were social distancing and isolation and the medical resources were the number of beds to understand the pattern of the spread of COVID-19 as mentioned in Table 1.

Table 1 Intervention Scenarios

\begin{tabular}{|c|l|}
\hline Scenarios & \multicolumn{1}{|c|}{ Description } \\
\hline A & All measures \\
\hline B & Social distancing \\
\hline C & Case isolation \\
\hline D & Case isolation and social distancing \\
\hline E & No measures \\
\hline
\end{tabular}

We ran the model with a close population of 500 agents for 740 days and initially 1 infected agent. The behaviour over time of each variable is shown in Figure 3. Of particular interest is the decrease in the healthy population, the increase in the number of recovered and dead, while these variables eventually stabilise after about 14 months (420 days).

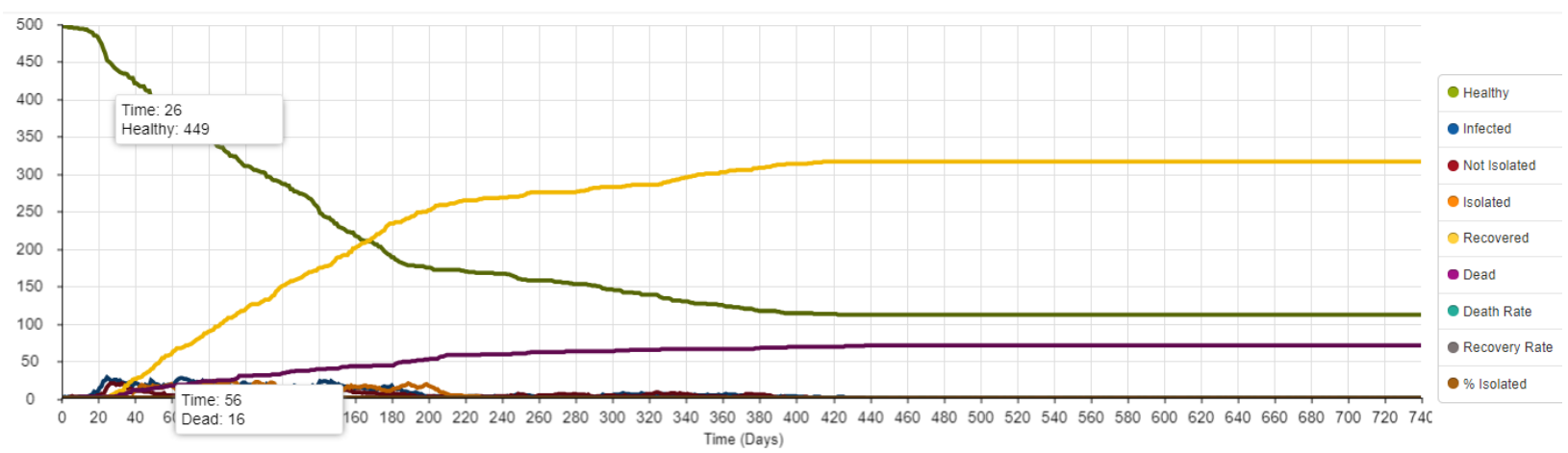

Figure 3 Illustration of the Demo Model

\subsection{Results}

This was done under five scenarios of pandemic COVID-19 where we considered different populations and different lengths of the pandemic with various interventions: no support, all, social distancing only, Isolation only, social distancing, and isolation only. The number of deaths (556) is the highest with no support scenario, lowers with isolation and social distancing scenarios, and is the lowest with all measures (243). Results are shown in Table 2.

Table 2 Results for all scenarios

\begin{tabular}{|c|c|c|c|c|}
\hline $\begin{array}{l}\text { Scenario A } \\
\text { (with all measures) }\end{array}$ & $\begin{array}{l}\text { Scenario B } \\
\text { (social distancing) }\end{array}$ & $\begin{array}{l}\text { Scenario C } \\
\text { (case isolation) }\end{array}$ & $\begin{array}{l}\text { Scenario D (case } \\
\text { isolation \& Soc Dist) }\end{array}$ & $\begin{array}{l}\text { Scenario E } \\
\text { (no measure) }\end{array}$ \\
\hline $\begin{array}{l}\text { Highest number } \\
\text { infected: } 26 \\
\text { Highest number } \\
\text { isolated: } 19 \\
\text { Recovered: } 839 \\
\begin{array}{l}\text { Death: } 243 \\
\text { Length of the } \\
\text { pandemic: } 752 \text { days }\end{array}\end{array}$ & $\begin{array}{l}\text { Highest number } \\
\text { infected: } 24 \\
\text { Recovered: } 1061 \\
\text { Death: } 317 \\
\text { Length of the } \\
\text { pandemic: } 998 \text { days }\end{array}$ & $\begin{array}{l}\text { Highest number } \\
\text { infected: } 56 \\
\text { Highest number } \\
\text { isolated: } 56 \\
\text { Recovered: } 791 \\
\begin{array}{l}\text { Death: } 245 \\
\text { Length of the } \\
\text { pandemic: } 537 \\
\text { days }\end{array}\end{array}$ & $\begin{array}{l}\text { Highest number infected: } \\
28 \\
\text { Highest number isolated: } \\
18 \\
\text { Recovered: } 977 \\
\text { Death: } 257 \\
\text { Length of the pandemic: } \\
1024 \text { days }\end{array}$ & $\begin{array}{l}\text { Highest } \\
\text { number } \\
\text { infected: } 150 \\
\text { Recovered: } \\
1344 \\
\text { Death: } 556 \\
\text { Length of the } \\
\text { pandemic: } \\
\text { 280 days }\end{array}$ \\
\hline
\end{tabular}




\subsection{Validation}

In our project, given that historical data is available for the epidemic spread in the Hubei region, we used data validity to validate our model.

Model validation was carried out in R: we compared the predicted number of deaths and recoveries (scenario A) in the Hubei region with the actual case data available. We found a strong correlation between the model and the Hubei data for both the number of deaths $($ Corr $=0.959)$ and the recoveries $($ Corr $=0.958)$. We further tested the model by performing a t-test. For both recovered individuals and deaths, the p-value was $<0.00001$, indicating a highly significant result. These results overall confirm that our model is a valid representation of the pandemic spread in the Hubei region.

\section{OUTPUT ANALYSIS BY COMPARING SCENARIOS AND HYPOTHESIS TESTING}

It may be mentioned that different interventions have a significant impact on the infected, recovered, isolated, and not isolated and death scenarios which is the beauty of our model. We see that the death rate is the highest as expected with no support scenario and the lowest with the isolation and social distancing scenario (Table 3 and Figure 4).

Table 3 Output Analysis with different scenarios

\begin{tabular}{|c|l|c|c|c|c|c|c|c|}
\hline SN & $\begin{array}{c}\text { Intervention } \\
\text { Support Name }\end{array}$ & $\begin{array}{l}\text { Mean } \\
\text { Infected }\end{array}$ & $\begin{array}{l}\text { Mean } \\
\text { Isolated }\end{array}$ & $\begin{array}{l}\text { Var. } \\
\text { Infected }\end{array}$ & Recovd. & Dead & $\begin{array}{l}\text { Total } \\
\text { Cases }\end{array}$ & $\begin{array}{l}\text { Death } \\
\text { Rate }\end{array}$ \\
\hline A A & $\begin{array}{l}\text { Social Distancing } \\
+\quad \text { Case Isolation + } \\
\text { Extra Hospital } \\
\text { Beds }\end{array}$ & 8 & 5 & 40.213 & 839 & 243 & 1082 & $22.5 \%$ \\
\hline $\mathrm{B}$ & Social Distancing & 8 & 0 & 39.164 & 1061 & 317 & 1378 & $23.0 \%$ \\
\hline $\mathrm{C}$ & Case Isolation & 8 & 7 & 183.19 & 791 & 245 & 1036 & $23.6 \%$ \\
\hline $\mathrm{D}$ & $\begin{array}{l}\text { Case Isolation + } \\
\text { Social Distancing }\end{array}$ & 10 & 6 & 38.733 & 977 & 257 & 1234 & $20.9 \%$ \\
\hline $\mathrm{E}$ & None & 11 & 0 & 754.47 & 1344 & 556 & 1900 & $29.3 \%$ \\
\hline
\end{tabular}

Figure 4 Scenarios Death Rate

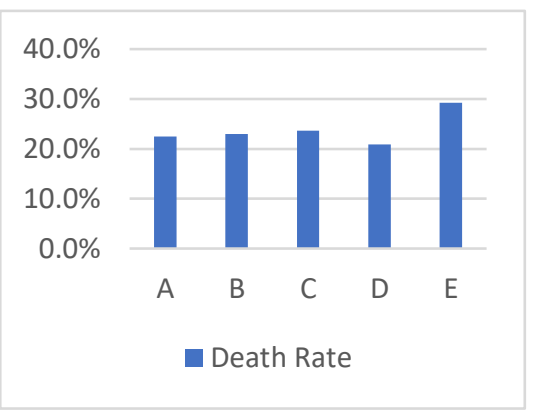

Hypothesis testing showed that any action taken has a significant effect on the number of people infected, the number of recoveries, and the number of deaths. This was because testing all scenarios against the base scenario (no effects) rejected the null hypothesis that these were equal to the volumes for scenario E. However, it should be noted that there is some volatility in the results. Some scenarios that we would expect to give relatively better performance (A vs. D) did not provide these results.

A potential next step would be to run more simulations so that there would be less volatility. However, it does appear that the acts of case isolation and social distancing together do affect, suggesting that government policies as they are should work (Strochlic and Champine, 2020).

\subsection{Sensitivity Analysis of Death and Infection Rate}

Further simulations were run based on Scenario A to examine the sensitivity of the death rate (Table 4). This was done by reducing the death rate in this scenario by $10 \%$. Instead of changing the death rate, the infection rate was reduced by $10 \%$ (Table 5). This implies that reducing the infection rate is a key measure to avoid the spread of the virus, with measures such as social distancing. This gives a sensitivity of 0.91 for the death rate, showing that parameters that change the death rate do come through in the actuals.

Table 4 Sensitivity Analysis of the Death Rate

\begin{tabular}{|c|c|}
\hline Scenario & Death Rate \\
\hline All measures & $22.5 \%$ \\
\hline $\begin{array}{c}\text { All measures, death rate } \\
\text { reduced by } 10 \%\end{array}$ & $20.4 \%$ \\
\hline
\end{tabular}

Table 5 Sensitivity Analysis of the Infection Rate

\begin{tabular}{|c|c|}
\hline New infection rate & $\mathbf{0 . 3 7 4}$ \\
\hline Previous infection rate & 0.4328 \\
\hline Sensitivity & 0.86414 \\
\hline
\end{tabular}

\section{CONCLUSION}

The field of computational epidemiology has arisen as a new branch of epidemiology to understand epidemic transmission patterns and to help in planning precautionary measures. The proposed model 
simulates the effect of pandemic COVID-19 outbreaks in Hubei, China. The model can be easily customised to study the pandemic spread of any other infectious disease by merely adjusting the model parameters. Deployment of a proper combination of control strategies can limit pandemic chaos and reduce fatalities and substantial economic damage. Further work on the proposed model includes other parameters like the number of tests per population, impact with open-air treatment (Vitamin D impact), the optimum number of medical staff and resources, and age-gender-medical history to decode the pandemic outbreak waves.

\section{REFERENCES}

Ahmed, A., Greensmith, J., and Aickelin, U. (2013). Variance in System Dynamics and Agent-Based Modelling Using the SIR Model of Infectious Disease. ResearchGate. Available from https://www.researchgate.net/publication/247153200_Variance_in_System_Dynamics_and_Agen t_Based_Modelling_Using_the_SIR_Model_of_Infectious_Disease [Accessed 4 May 2020].

Bai, N. (2020). How the New Coronavirus Spreads and Progresses - And Why One Test May Not Be Enough. How the New Coronavirus Spreads and Progresses - And Why One Test May Not Be Enough | UC San Francisco. Available from https://www.ucsf.edu/news/2020/02/416671/hownew-coronavirus-spreads-and-progresses-and-why-one-test-may-not-be-enough [Accessed 22 April 2020].

Blume, L. (2015). Agent-Based Models for Policy Analysis. National Academies Press (US). Available from https://www.ncbi.nlm.nih.gov/books/NBK305903/ [Accessed 4 May 2020].

Bonabeau, E. (2002). Agent-based modeling: Methods and techniques for simulating human systems. Proceedings of the National Academy of Sciences, 99 (suppl 3), 7280-7287. Available from https://doi.org/10.1073/pnas.082080899 [Accessed 5 May 2020].

Bordehore et al. (2020). Understanding COVID-19 spreading through simulation modelling and scenario comparison: preliminary results. | medRxiv. Available from https://www.medrxiv.org/content/10.1101/2020.03.30.20047043v1.full.pdf+html [Accessed 21 April 2020].

Buchholz, K. (2020). Infographic: What Share of the World Population Is Already on COVID-19 Lockdown? Statista Infographics. Available from https://www.statista.com/chart/21240/enforcedcovid-19-lockdowns-by-people-affected-per-country/ [Accessed 22 April 2020].

Cecconi, F. and Barazzetti, A. (2020). Agent-based simulation models are applied to social behaviours determining the dynamics of pandemics. UCM. Available from https://ucm.edu.mt/en/agent-based-simulation-model-applied-to-social-behaviors-determiningthe-dynamics-of-pandemics/ [Accessed 22 April 2020].

Chamie, J. (2020). World Populations: 2020 Overview | YaleGlobal Online. Available from https://yaleglobal.yale.edu/content/world-population-2020-overview [Accessed 22 April 2020].

Chen, B. et al. (2020). Visual Data Analysis and Simulation Prediction for COVID-19. 19.

CSSEGIS and Data. (2020). CSSEGIS and Data/COVID-19. Available from https://github.com/CSSEGISandData/COVID-19 [Accessed 22 April 2020].

Daley, D.J. (2008). Epidemic Modelling: An Introduction, Revised ed. edition. 1st paperback edition, reprinted 2005: Cambridge University Press.

ECDC. (2020). Disease background of COVID-19. European Centre for Disease Prevention and Control. Available from https://www.ecdc.europa.eu/en/2019-ncov-background-disease [Accessed 22 April 2020].

Forrester, J.W. (1961). Industrial dynamics. Cambridge, Mass.: M.I.T. Press.

Ghaffarzadegan, N. and Rahmandad, H. (2020). Simulation-based Estimation of the Spread of COVID-19 in Iran. medRxiv, 2020.03.22.20040956. Available from https://doi.org/10.1101/2020.03.22.20040956 [Accessed 21 April 2020].

Hack, J. et al. (2019). Epidemic Spreading in Urban Areas Using Agent-Based Transportation Models. ResearchGate. Available from https://www.researchgate.net/publication/332284749_Epidemic_Spreading_in_Urban_Areas_Usi ng_Agent-Based_Transportation_Models [Accessed 7 March 2020].

Hethcote, H.W. (2000). Mathematics of Infectious Diseases. SIAM Review, 42 (4), 599-653. Available from https://doi.org/10.1137/S0036144500371907 [Accessed 9 March 2020]. 
Hossain et al. (2017). Modelling of a Super-Spreading Event of the Mers-Corona Virus during the Hajj Season using Simulation of the Existing Data. ResearchGate. Available from https://www.researchgate.net/publication/320736530_Modeling_of_a_SuperSpreading_Event_of _the_MersCorona_Virus_during_the_Hajj_Season_using_Simulation_of_the_Existing_Data [Accessed 21 April 2020].

Johns Hopkins CSSE. (2020). Coronavirus COVID-19 (2019-nCoV). https://systems.jhu.edu/. Available from https://www.arcgis.com/apps/opsdashboard/index.html\#/bda7594740fd40299423467b48e9ecf6 [Accessed 22 April 2020].

Khalil M. et al., K. (2012). Agent-based modelling for pandemic influenza in Egypt. ResearchGate. Available from https://www.researchgate.net/publication/224136840_An_agentbased_modeling_for_pandemic_influenza_in_Egypt [Accessed 29 February 2020].

Lin, Q. et al. (2020). A conceptual model for the coronavirus disease 2019 (COVID-19) outbreak in Wuhan, China with individual reaction and governmental action. International Journal of Infectious Diseases, 93, 211-216. Available from https://doi.org/10.1016/j.ijid.2020.02.058 [Accessed 3 April 2020].

Lynch, P. (2020). Coronavirus: Modelling the evolution of a viral outbreak. The Irish Times. Available from https://www.irishtimes.com/news/science/coronavirus-modelling-the-evolutionof-a-viral-outbreak-1.4197391 [Accessed 21 April 2020].

Macal, C. and North, M. (2006). Tutorial on Agent-Based Modelling and Simulation PART 2: How to Model with Agents. Proceedings of the 2006 Winter Simulation Conference. December 2006. Monterey, CA, USA: IEEE, 73-83. Available from https://doi.org/10.1109/WSC.2006.323040 [Accessed 29 February 2020].

Mathematical Modeling of COVID-19: 4/17/20 Update with Mac Hyman. (2020). Available from https://www.youtube.com/watch?v=hlzXMFyuhwU [Accessed 3 May 2020].

Neergaard, L. (2020). Coronavirus Death Rate Still Uncertain as Mild Cases Go Unreported. HuffPost. Available from https://www.huffpost.com/entry/coronavirus-deathrate_n_5e5ff494c5b6f4b39568be17 [Accessed 22 April 2020].

Oberkampf, W.L., and Trucano, T.G. (2002). Verification and validation of computational fluid dynamics. Progress in Aerospace Sciences, 38 (3), 209-272. Available from https://doi.org/10.1016/S0376-0421(02)00005-2 [Accessed 4 May 2020].

Perez, L., and Dragicevic, S. (2009). An agent-based approach for modelling dynamics of contagious disease spread. International Journal of Health Geographics, 8 (1), 50. Available from https://doi.org/10.1186/1476-072X-8-50 [Accessed 6 March 2020].

Purohit, K. (2020). Misinformation and fake news spark India's coronavirus fears. Available from https://www.aljazeera.com/news/2020/03/misinformation-fake-news-spark-india-coronavirusfears-200309051731540.html [Accessed 22 April 2020].

Reuters. (2020). Wuhan closes makeshift hospital as new coronavirus cases in China drop sharply. Reuters, 2 March. Available from https://uk.reuters.com/article/uk-health-coronavirus-china-tollid UKKBN20P023 [Accessed 22 April 2020].

Stan, U. (1987). "John Von Neumann and the Monte Carlo method." Los Alamos Science, 15, (special issue), 131-136. Available from https://permalink.lanl.gov/object/tr?what=info:lanlrepo/lareport/LA-UR-88-9068 [Accessed 3 May 2020].

Stehlé, J. et al. (2011). Simulation of an SEIR infectious disease model on the dynamic contact network of conference attendees. BMC Medicine, 9 (1), 87. Available from https://doi.org/10.1186/1741-7015-9-87 [Accessed 3 May 2020].

Stevens, H. (2020). Why outbreaks like coronavirus spread exponentially, and how to "flatten the curve" - Washington Post. Available from https://www.washingtonpost.com/graphics/2020/world/corona-simulator/ [Accessed 21 April 2020].

Strochlic, N. and Champine, R.D. (2020). How some cities 'flattened the curve' during the $1918 \mathrm{flu}$ pandemic. History. Available from https://www.nationalgeographic.com/history/2020/03/howcities-flattened-curve-1918-SPANISH-flu-pandemic-coronavirus/ [Accessed 22 April 2020]. 
Vynnycky, E. and White, R.G. (2010). An introduction to infectious disease modelling. Available from http://anintroductiontoinfectiousdiseasemodelling.com/chapters/chapter-1/ [Accessed 22 April 2020].

Wainwright, J. and Mulligan, M. (2013). Environmental Modelling: Finding Simplicity in Complexity, 2nd Edition | Wiley. Wiley.com. Available from https://www.wiley.com/en$\mathrm{gb} /$ Environmental+Modelling\%3A+Finding+Simplicity+in+Complexity\%2C+2nd+Edition-p9780470749111 [Accessed 22 April 2020].

WHO. (2020). sitrep-ncov. Available from https://www.who.int/docs/defaultsource/coronaviruse/situation-reports/20200121-sitrep-1-2019-ncov.pdf [Accessed 22 April 2020].

Wu Pei Lin and Lin, as told to W.P. (2020). 'The city is suffocating': a diary of the Wuhan coronavirus lockdown. The Guardian, 31 January. Available from https://www.theguardian.com/world/2020/jan/31/the-city-is-suffocating-diary-of-the-wuhancoronavirus-lockdown [Accessed 22 April 2020].

Zhong, S., Huang, Q. and Song, D. (2009). Simulation of the spread of infectious diseases in a geographical environment. Science in China Series D: Earth Sciences, 52 (4), 550-561. Available from https://doi.org/10.1007/s11430-009-0044-9 [Accessed 3 May 2020].

\section{AUTHOR BIOGRAPHIES}

MD ZAMANUR RAHMAN recently received an MSc in Business Intelligence and Analytics (BI\&A with distinction from the University of Westminster, UK. He also holds an MBA, MCom, MPhil, and $\mathrm{PhD}$ (IBA, DU). Before that, he worked in different private and public universities in Bangladesh including IBA, the University of Dhaka as a professor in the area of Accounting and Research as well as in Civil Service of the Government of Bangladesh (GoB) and different foreign funded (CEC, UNDP, DFID) projects.

CHRISTOPHER HITCHIN received a BSc (Hons) in Mathematics from the University of Warwick in 2014. He is currently in the process of completing an MSc in BI\&A at the University of Westminster. He is currently a Pricing \& Underwriting Analyst at Direct Line Group, one of the UK's leading general insurance companies, with previous experience as a Systems Analyst for an IT platforms provider specialising in the life insurance industry.

KATHRYN LIDDLE received a BSc in Ecology and Wildlife Conservation from Bournemouth University in 2013 and an MSc in BI\&A (Distinction) from the University of Westminster in 2020. She has worked as an analyst in various organisations including Tesco, Skanska, and Biztory.

SIFI BAHULEYAN received a BSc in Psychology from Brunel University in 2013 and is currently in the process of completing an MSc in BI\&A. She has been working for several years at NHS organisations, currenty as quality improvement coach at Camden and Islington NHS Foundation Trust.

OLAWALE BETIKU received a BSc in business studies with first-class honours at the university of West London, 2016. He is in the process of completing an MSc in BI\&A at the University of Westminster and is currently a successful entrepreneur, forex trading, stocks, and cryptocurrency.

THIERRY CHAUSSALET received a $\mathrm{PhD}$ in Probability and Stochastic Processes from North Carolina State University (USA) in 1993. He founded the Health and Social Care Modelling Group at the University of Westminster in 1998, became Professor in 2007, and has been course leader of the MSc BI\&A since 2010. His research interests are around intelligent data-driven methods to model management and decision making processes. He serves on the Editorial Board of various healthcare modelling and informatics journals. He has been a member of the EPSRC Peer Review College, an expert evaluator for the EU FP7 ICT programme, and is a member of the NIHR Peer Review panel. 